\title{
PHENYLKETONURIA WITH A STUDY OF THE EFFECT UPON IT OF GLUTAMIC ACID
}

\author{
BY \\ L. I. WOOLF and D. G. VULLIAMY \\ From The Hospital for Sick Children, Great Ormond Street, London
}

(Received for Publication January 1, 1951)

Since Fölling (1934) in Norway first drew attention to the association of mental defect with the excretion of phenylpyruvic acid in the urine, this syndrome has been reported from many parts of the world. In institutions for mental defect it has become possible to separate, by a simple urine test, a group of patients of the lower grades who are found also to have certain general physical characteristics in common. Names for this inborn error of metabolism range from the descriptive but unwieldy term 'phenylpyruvic oligophrenia' to 'Fölling's disease.' 'Phenylketonuria' was suggested by Quastel and adopted by Penrose (1935).

It has been studied in great detail as a problem in genetics, chiefly by Penrose (1946) and Munro (1947) in Britain, and by Jervis (1939) in the U.S.A. The conclusion reached is that it is inherited as a Mendelian recessive characteristic. In a large series of families, it is found that the proportion of affected siblings is about one in four, and that there is a greater than average incidence of consanguinity amongst the parents (in Munro's series, 10\% compared with a normal rate of $1 \%$ ). Fortunately the fertility of phenylketonuric patients is so low that it rarely occurs in both parents and offspring. In a series of 50 cases (Jervis, 1937) only one parent was definitely affected.

- It has been suggested (Penrose, 1935) that depression with persecutory ideas and other types of mental disturbance are more common amongst the parents of these patients than amongst the average population. Munro (1947) compared the parents from 47 phenylketonuric families with the parents of a large group of idiots and imbeciles of. other types, and found the incidence of psychoses to be about the same.

\section{Incidence}

The incidence can be estimated only from the proportion of cases discovered amongst mental defectives in institutions. Munro (1947) finds that it occurs in $1.2 \%$ of idiots and imbeciles and, knowing the approximate number of these in the general population, calculates a total incidence of between 2 and 6 per 100,000 in Britain. This excludes the very few who are above the imbecile grade. Jervis (1937) finds phenylketonuria in $0.522 \%$ of mentally defective patients of all grades in institutions in the U.S.A., as compared with $0.04 \%$ in Switzerland (Brugger, 1942) and 1.34\% in Norway (Fölling, 1934).

Such estimates are inevitably approximate, and are not strictly comparable because of the variations in the proportion and grade of mentally defective patients who are admitted to institutions in different communities. Some of the difference may, however, be racial, as no cases have been reported amorigst Jews or Negroes.

\section{Age}

Phenylketonuria has not been demonstrated at birth, but Munro (1950) in a personal communication states that he has seen it at the age of 6 weeks. Apart from this, Cases 1 and 5 here described are among the youngest on record at the time of writing.

In a suspected case, aged 2 months, reported by Delay, Pichot, Delbarre, and Taseel (1948), the youngest member of an affected family, it is said of the urine that 'La réaction de Fölling n'y est pas franchement positive.'

\section{Clinical Picture}

Though it is essential to find phenylpyruvic acid in the urine before making the diagnosis, there are certain rather inconstant clinical features which, occurring together in one patient, may suggest. it to the observer so strongly that the urine examination is merely a confirmatory test.

Those who see these patients frequently can 
recognize a facial similarity in many of them which is difficult to define. One of the most constant physical features is the relative lack of pigment in the hair and eyes. In one series (Jervis, 1937) $86 \%$ were blondes and $66 \%$ had blue eyes. A blonde patient, 38 of whose relatives were dark, is described by Delay and Pichot (1947), and another patient of Sicilian parentage is cited, members of whose family had been dark for three generations. This suggests that the fairness of the hair is related to the biochemical disorder. Cranial measurements tend to be small in some cases, but with no characteristic skull shape. The large size of the maxilla, which is particularly noticeable in Case 3 (Fig. 3b), may or may not be accompanied by wide spacing of both upper and lower incisor teeth (Fig. 2b). Roughness of the skin, with either a dry papular eruption on the extensor aspects or diffuse eczematous patches, is also common. There may be kyphosis and dwarfing in later childhood. Reports of abnormal signs in the central nervous system differ. In one large series of patients fully examined $70 \%$ were said to have increased muscle tone and exaggerated deep reflexes, the plantar responses being flexor (Jervis, 1937). Others disagree, and state that ordinarily there is no increase in muscle tone (Penrose, 1949). Certainly it was not a feature of any one of our five cases. Repetitive movements, particularly of the fingers, are common, but they are organized and are not suggestive of release of cortical control as in choreo-athetosis. The gait, when walking is possible, is clumsy and the body is held rather rigidly, bent forwards. Petit mal, or less commonly, major epilepsy, are frequent complaints.

Examinations of the cerebrospinal fluid have shown no abnormality, apart from a high content of phenylalanine (Jervis, Block, Bolling, and Kanze, 1940). Air encephalograms in 11 cases (Jervis, 1937) showed in some a moderate dilatation of the ventricles, and in others an increased amount of air in the subarachnoid space. Electroencephalograms are not characteristic, but, as in our cases, frequently show evidence of epilepsy.

On the whole these patients are not as unattractive physically as one would expect from the severity of the mental defect. Most are idiots with intelligence quotients below 20, the remainder being mostly imbeciles, with a very occasional case of higher grade.

Galactose-tolerance tests have been carried out in nine cases (Cowie, 1950, personal communication) and in three of these the results indicated a considerable degree of liver dysfunction.

\section{The Urine Test}

Testing for the presence of phenylpyruvic acid is so simple that it can easily be done as a routine in

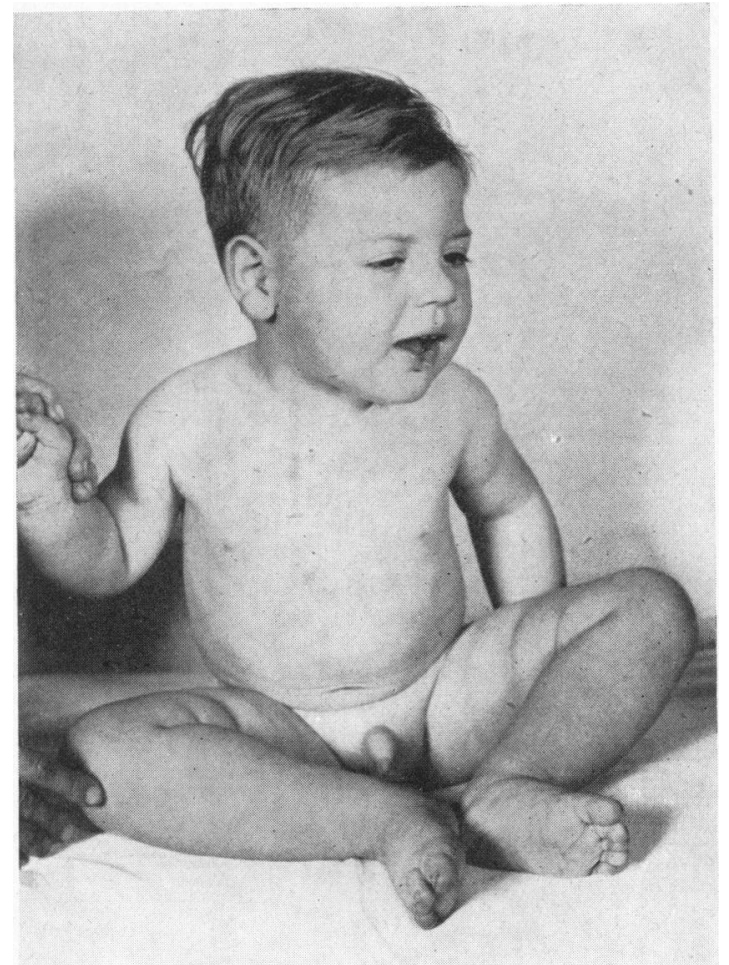

Fig. 1.-Case 1 at 23 months.

all patients with mental defect attending an outpatient clinic. To $5 \mathrm{ml}$. of urine $0.5 \mathrm{ml}$. of $5 \%$ ferric chloride is added. A deep green, which reaches a maximum intensity within three minutes and fades gradually, is a positive result.

\section{Prognosis}

The biochemical disturbance does not seem to have any deleterious effect upon bodily health, and the mental state does not progressively deteriorate after the age of 1 year. There is, however, no record of a patient having shown any striking increase in intelligence.

The chance of a subsequent child being also affected is one in four.

\section{Pathology}

Reports, of necropsies are remarkably scarce and at the time of writing only two are known to have been published.

The first (Penrose, 1939) was of a boy of 9 years who died of intercurrent pulmonary infection. The findings of importance were a brain of normal size and weight with no definite histological abnormality, and the presence of many small, tense swellings resembling neurofibromata along nerve trunks, 
particularly the vagi, phrenics, the pudendal and coeliac plexuses, and the left sciatic nerve. The liver was reported as normal.

The second (Coquet, Myle, Nyssen, and van Bogaert, 1944), a ged 12 years, died in 'cachexia,' the body being greatly dehydrated. Although microscopic examination of the brain was carefully carried out, the findings were mostly such as might be explained by the general cachectic state at death. There was, however, some glial proliferation in the region of the centrum ovale, and some lymphocytic cuffing around vessels in the leptomeninges and cortex. The liver showed 'perilobular' fatty degeneration and congestion in the intertrabecular capillaries.

\section{Biochemical Basis}

The error in metabolism lies in the inability of these patients to convert phenylalanine to tyrosine, the normal pathway for phenylalanine metabolism (reaction A). The phenylalanine, which has a high kidney threshold, accumulates in the blood and cerebrospinal fluid, and 'spills over' into the urine (Jervis, 1947). Some of the phenylalanine is converted, either by transamination or by oxidative deamination, to phenylpyruvic acid (reaction B); some of this is reduced to phenyl-lactic acid (reaction $\mathrm{C}$ ), and probably undergoes other changes. Both of these acids have low kidney thresholds and appear in the urine in large amounts, but cannot be detected in the blood or cerebrospinal fluid by the methods at present available.

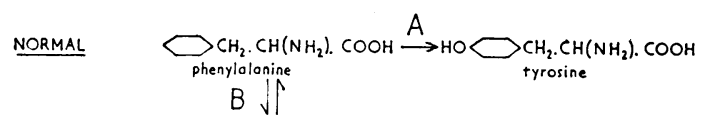

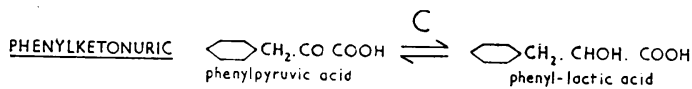

Reaction A takes place in the normal liver, while nothing is known of the sites of reactions B and C. An alternative view is that phenylpyruvic acid is a normal intermediate product of phenylalanine metabolism, and is normally converted to p. -hydroxyphenylpyruvic acid, and this in turn to tyrosine. On this supposition the metabolic block in these patients lies in the inability to hydroxylate phenylpyruvic acid (Penrose and Quastel, 1937).

\section{Case Reports}

Case 1. Michael H. (Fig. 1), aged 18 months, was born by normal delivery after a normal pregnancy and weighed $7 \mathrm{lb} .5 \mathrm{oz}$. Nothing abnormal was noticed in the newborn period.

The father and mother were of normal intelligence and unrelated, having been born in widely different parts of the country. A brother, aged 6 years (Case 2), was an idiot with phenylketonuria; there were no other siblings and there had

FIG. 2a.-Case 2, at 6 years, showing bizarre posture.

FIG. 2b.-Case 2, to show the wide space between the lateral incisors, the central incisors having been removed by trauma.

FIG. 2a.

FIG. $2 b$.

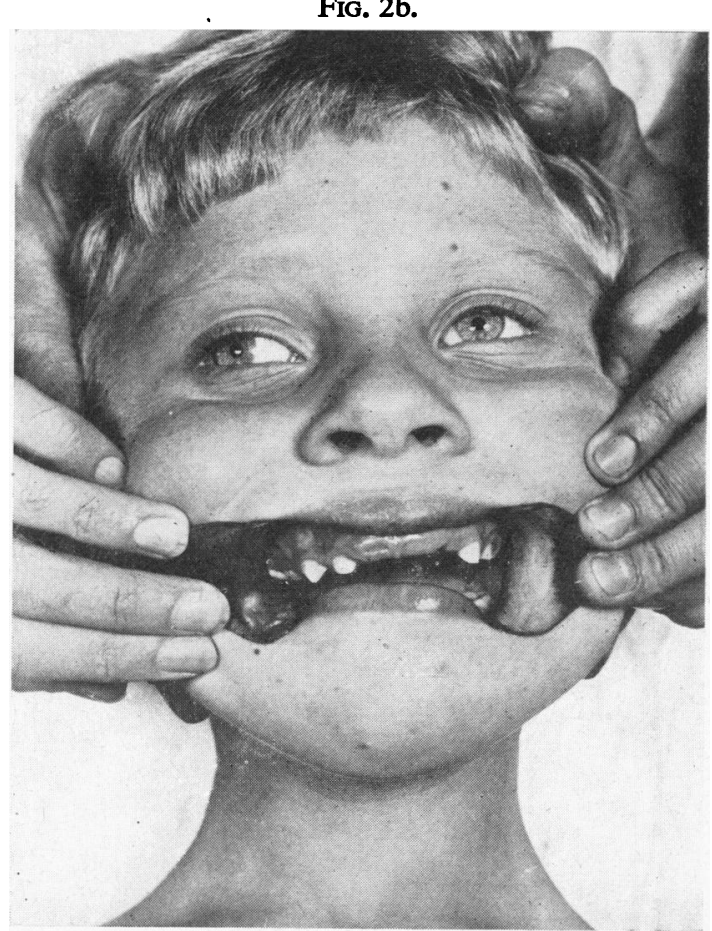


been no miscarriages. No other cases of mental disease on either side of the family were known.

The boy was slow in development, being able to hold his head erect at 5 months and to sit unaided at 1 year. Walking was still not achieved when last seen at $2 \frac{1}{2}$ years. He was unable to feed himself, and was incontinent of urine and faeces. Since the age of 1 year he had been having 10 to 30 attacks of petit mal a day.

When the boy was examined, he had the appearance of a strong, healthy child with a normal facies not obviously suggesting mental defect. His hair was fair, eyes brown, and skin rough and dry with a pimply eruption on the extremities. The head was of normal shape and measured 18 inches in circumference, the fontanelles being closed. There were constant movements of the head and limbs, similar to those of

Fig. 3a.-Case 3, at 10 years, showing dry eczematous patches, moles, and scratch marks on the trunk.

Fig. 3b.-Case 3, to show prominence of the maxilla.

FIG. 3b.

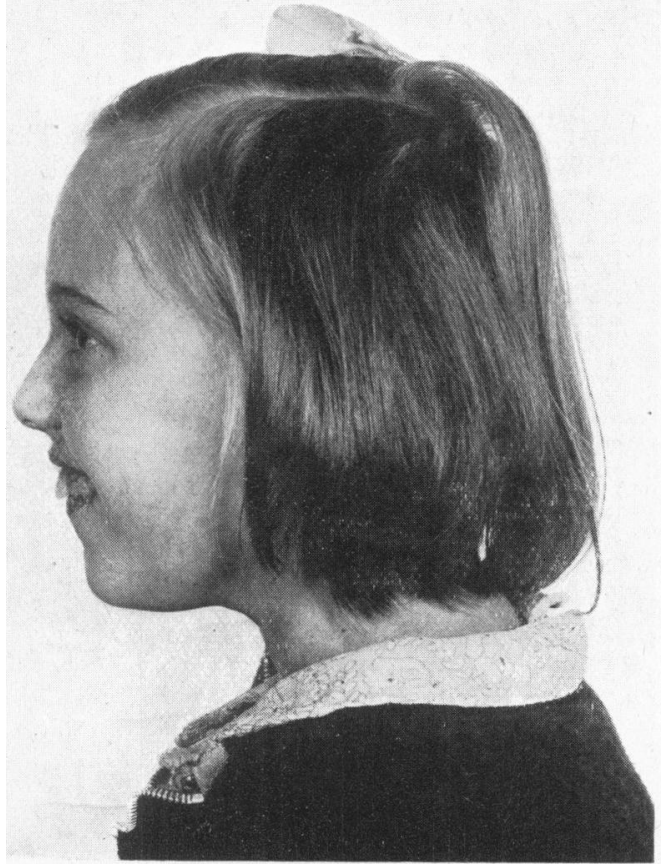

a vigorous baby of 6 months of age and not suggestive of. chorea or athetosis.

Concentration on interesting objects was transient, though vision was certainly present. There was no evidence of deafness, and all the other cranial nerves were normal. Although all deep reflexes were brisker than usual, there was no spasticity or weakness. An electroencephalogram showed spike-and-wave complexes typical of petit mal, but no other specific abnormality.

Case 2. John H. (Fig. 2), aged 6 years, the elder brother of the patient in Case 1, was much more severely defective. Born by normal delivery after a normal pregnancy, he was noticed to have a squint soon after birth, and when he was taken to hospital at 7 months old a diagnosis of probable mental defect was made. He began to sit up unaided at 3 years, crawled at $3 \frac{1}{2}$ to 4 years, and walked at $5 \frac{1}{2}$ years. He was completely incontinent, unable to feed himself, or to play with even simple toys.

When the boy was examined he presented the picture of gross mental defect, with complete lack of interest in the observer or in surrounding objects; there were purposeless, repetitive movements, sometimes of a self-destructive Fig. 3a. 
of 1 year she was noticed to be slightly abnormal: tensing and relaxing movements of the hands, and rolling of the head were observed. She sat unaided at 16 months, walked at 20 months, fed herself at 2 years, and by 3 years was able to fetch her mother ordinary household objects when asked. At the time of this examination, she was able to wash-up, mind the baby, and do other odd jobs in the house. Development of speech seemed to have lagged behind other functions, and she could say only a few single words, making herself understood mainly by gestures and unintelligible noises. She was clean in her habits, and only occasionally wet the bed at night.

She was a tall, thin child of fairly normal appearance, not obviously mentally defective. The maxilla was prominent, but the teeth were not widely spaced. The skull was of normal shape, and measured 201 in. in circumference; the hair was fair but becoming darker, and the eyes bluish-grey. The skin was dry and showed numerous scratch marks and many small pigmented moles. There was little or no repetitive movement, but she spent much time humming and singing tunelessly.

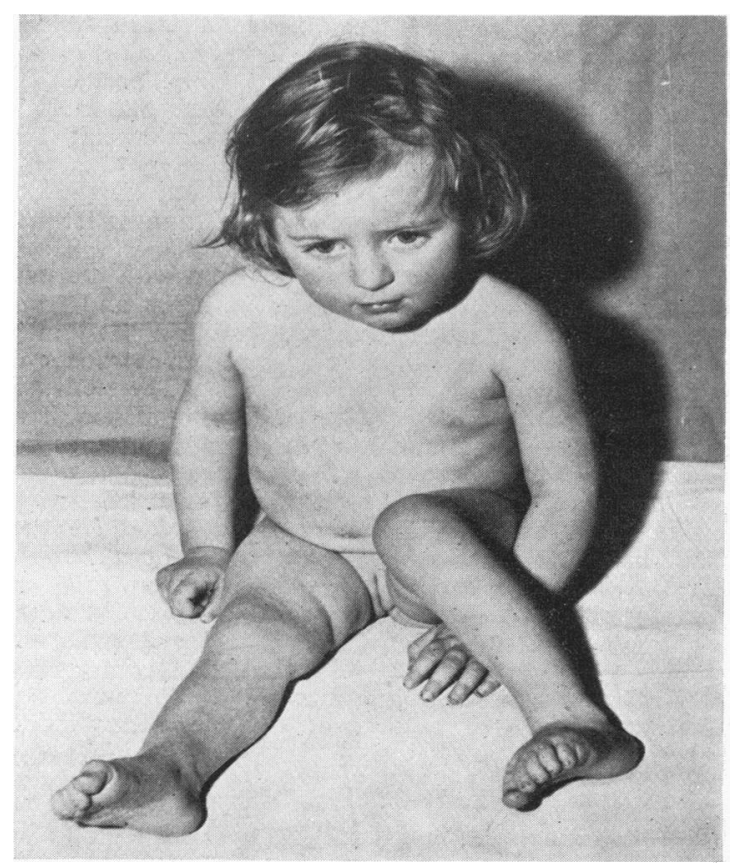

FIG. 5.-Case 5, at 23 months.

Walking was normal, except for slight clumsiness, and there were no abnormal neurological signs.

Case 4. Jennifer W. (Fig. 4), sister of Case 3, aged 4 years, was born by normal labour after a normal pregnancy. She was regarded as a normal healthy infant, and won two prizes at baby shows at the age of 6 months. She sat unaided at 11 months and walked at $1 \frac{1}{2}$ years. Having failed to talk by 2 years she was thought to be a little backward, and at 3 years her progress seemed to cease. Speech had not developed at the time of this examination, but she was able to indicate simple wants. She was incontinent of urine and faeces, and unable to feed herself. Her play was that of a child of about 18 months; for example, she tore up paper, and held dolls, but did not play intelligently with them. She was said to be good-natured and amenable.

She was a fair-haired child with blue-grey eyes, and her general appearance showed no signs of obvious mental defect. The skin, teeth, and jaws were normal, but the skull was brachycephalic, and the maximum circumference was $18 \frac{3}{4}$ in. Apart from occasional outbursts of screaming and hyperactivity, there were no repetitive abnormal movements, and no abnormal neurological signs.

Case 5. Moira D. (Fig. 5), aged 18 months, was born by normal delivery after a normal pregnancy, and weighed $7 \mathrm{lb} .3 \mathrm{oz}$. Nothing abnormal was noticed in the newborn period.

The father and mother were of normal intelligence and not related. Both were of Irish parentage, but from 
different districts. There was one brother aged $8 \frac{1}{2}$ years, a proven case of phenylketonuria living in an institution, and one sister aged $2 \frac{1}{2}$ of normal intelligence, with congenital dislocation of the hips. There had been no miscarriages. The girl's motor development had been slow; sitting without support was achieved by 13 months, and no attempt at walking had been made by the time of this examination. For the past six months frequent attacks of petit mal had occurred.

She was a fair-haired, blue-eyed child with constant, restless, incoordinated movements of limbs and trunk. The skull was of normal shape, measuring $18 \frac{1}{2}$ in. in circumference. The skin was dry, and numerous small papules were present on both forearms. The teeth were normally spaced and there was no enlargement of the maxilla. She was uninterested in her surroundings, and did not concentrate on objects presented to her, though she followed a light with her eyes for brief periods. Abnormal grunting sounds and grimaces were frequent, and limb movements were reminiscent of a baby of 6 to 9 months. Although deep reflexes were brisk and plantar reflexes extensor, no definite increase in muscle tone was present, and no other abnormal signs were found.

An elextroencephalogram showed spike-and-wave activity typical of petit mal, but no other specific abnormality.

\section{Further Investigations}

Glutamic acid feeding is said to depress the blood level of other amino-acids (Christensen, Streicher, and Elbinger, 1948). In view of this fact, and of encouraging reports of treatment of mental defect with glutamic acid (Albert, Hoch, and Waelsch, 1946; Zimmerman, Burgemeister, and Putnam, 1947) including one case of phenylketonuria in France (Delay, Pichot, and Bertagna, 1949), it was decided to measure the effect of the administration of this substance upon the blood phenylalanine and daily output of phenylalanine, phenylpyruvic and phenyl-lactic acid in urine. It was thought that should an alteration in these values be found, it might help to establish a link between the biochemical disorder and the mental retardation. The blood level and 24-hour excretion of phenylalanine and its breakdown products were determined before and after one week of glutamic acid feeding (Table 1). The molecular weights of phenylalanine, phenylpyruvic acid, and phenyl-lactic acid are so close that simple addition is a valid method of arriving at the total of all three compounds (Table 1). In Case 1 treatment was interrupted, permitting two sets of results to be obtained.

Phenylpyruvic acid content was determined by a ferric chloride method (Woolf, 1949, unpublished). Phenylalanine and phenyl-lactic acid contents were determined by means of the Kapeller-Adler reaction (Jervis, Block, Bolling, and Kanze, 1940). The apparent phenylalanine given here includes phenacetylglutamine (Woolf, 1951).

The blood phenylalanine concentration does not seem to be much altered, certainly not consistently reduced, by the glutamic acid fed at these dosage levels. In all except one case the total of phenylalanine and its breakdown products excreted is markedly increased after glutamic acid feeding. This could be partially, but not completely, explained by its apparent diuretic effect.

All the urine and blood specimens were examined by paper chromatography (Consden, Gordon, and Martin, 1944) for amino acids. Apart from the large amount of phenylalanine in all specimens, other amino acids were normal before glutamic acid feeding. After glutamic acid feeding blood glutamic acid rose considerably, and glutamine in urine rose somewhat less markedly.

Since it was thought that if any benefit were to be derived from glutamic acid it would be most likely to occur in the youngest patients, Cases 1 and 5 were given long term treatment after developmental age was assessed as accurately as possible by Gesell's norms.

In Case 1 the developmental age was estimated at 9 months when the chronological age was 23 months. After five months treatment with L-glutamic acid ranging from 9 to $16 \mathrm{~g}$. daily, a second assessment of developmental age was made, and an increase of only 4 to 6 weeks had occurred. After another six months of treatment there was little or no increase.

The second patient (Case 5) had a developmental age of about 8 months when she was 20 months old. After six months' treatment development was found to be no more than would be expected in a child with this degree of mental defect. Obviously, no definite conclusions can be drawn from two cases, but it seems unlikely that glutamic acid feeding, in a dosage which can easily be tolerated, produces the beneficial effect in phenylketonuria which was hoped for on theoretical grounds.

\section{Comment}

The relationship between the error in metabolism and the mental defect remains obscure. Other defects in intermediate metabolism of amino-acids, for example, alcaptonuria, do not have similar effects. It seems most probable that the phenylalanine, or one of its breakdown products, circulating in the blood in concentrations much higher than normal, depresses the activity of the higher mental centres.

If the amount of phenylalanine and its breakdown products could be reduced, normal cerebral function might result. Whether this would lead to recovery or not, would probably depend upon the duration of exposure of the brain to the injurious concentration of this substance.

Two possible methods of achieving this reduction seem worthy of investigation: restricting the phenylalanine intake in the diet to the basic minimum early in life; and increasing the rate of excretion of phenylalanine by administering a substance which would competitively reduce tubular reabsorption.

\section{Summary}

An account of the clinical and biochemical features of phenylketonuria is given and five cases 
TABLE 1

Measurements of the Excretion of Phenylalanine and its Breakdown Products Before and After Feeding GLUTAMIC ACID

\begin{tabular}{|c|c|c|c|c|c|c|c|c|}
\hline Patient & Weight & $\begin{array}{l}\text { Amount of } \\
\text { Glutamic } \\
\text { Acid } \\
\text { (g./day) }\end{array}$ & Specimen & Volume & $\begin{array}{c}\text { Phenylpyruvic } \\
\text { Acid } \\
\text { (mg./100 ml.) }\end{array}$ & $\begin{array}{l}\text { Phenylalanine } \\
(\mathrm{mg} . / 100 \mathrm{ml} \text { ) }\end{array}$ & $\begin{array}{c}\text { Phenyl-lactic } \\
\text { Acid } \\
\text { (mg./100 ml.) }\end{array}$ & $\begin{array}{c}\text { Total } \\
\text { Excreted } \\
\text { (mg./day). }\end{array}$ \\
\hline \multirow[t]{2}{*}{$\begin{array}{l}\text { Case } 1 \\
\text { M.H. }\end{array}$} & \multirow[t]{2}{*}{$\begin{array}{c}29 \mathrm{lb} . \\
3 \mathrm{oz} .\end{array}$} & 0 & $\begin{array}{l}\text { Urine } \\
\text { Plasma }\end{array}$ & 360 & 97 & $\begin{array}{l}87 \\
31\end{array}$ & 118 & 1,089 \\
\hline & & 9 & $\begin{array}{l}\text { Urine } \\
\text { Plasma }\end{array}$ & $\underline{470}$ & 81 & $\begin{array}{r}117 \\
39\end{array}$ & 86 & 1,335 \\
\hline \multirow{2}{*}{$\begin{array}{l}\text { Case } 1 \\
\text { M.H. }\end{array}$} & \multirow{2}{*}{$\begin{array}{l}29 \mathrm{lb} . \\
3 \mathrm{oz} .\end{array}$} & 0 & Urine & 440 & 74 & 82 & 70 & 999 \\
\hline & & 9 & $\begin{array}{l}\text { Urine } \\
\text { Serum }\end{array}$ & 560 & 113 & $\begin{array}{l}68 \\
31\end{array}$ & 84 & 1,485 \\
\hline \multirow[t]{2}{*}{$\begin{array}{l}\text { Case } 2 \\
\text { J.H. }\end{array}$} & \multirow[t]{2}{*}{$41 \mathrm{lb}}$. & 0 & $\begin{array}{l}\text { Urine } \\
\text { Serum }\end{array}$ & 554 & 74 & $\begin{array}{r}112 \\
26\end{array}$ & 169 & 1,963 \\
\hline & & 12 & $\begin{array}{l}\text { Urine } \\
\text { Serum }\end{array}$ & 1,036 & 53 & $\begin{array}{l}88 \\
21\end{array}$ & 100 & 1,565 \\
\hline \multirow[t]{2}{*}{$\begin{array}{l}\text { Case } 3 \\
\text { G.W. }\end{array}$} & \multirow[t]{2}{*}{$69 \mathrm{lb}}$. & 0 & $\begin{array}{l}\text { Urine } \\
\text { Serum }\end{array}$ & 750 & 100 & $\begin{array}{l}71 \\
21\end{array}$ & 94 & 1,987 \\
\hline & & 30 & $\begin{array}{l}\text { Urine } \\
\text { Serum }\end{array}$ & 875 & 100 & $\begin{array}{l}80 \\
26\end{array}$ & 68 & 2,370 \\
\hline \multirow[t]{2}{*}{$\begin{array}{l}\text { Case } 4 \\
\text { J.W. }\end{array}$} & \multirow[t]{2}{*}{$\begin{array}{l}36 \mathrm{lb} . \\
4 \mathrm{oz} .\end{array}$} & 0 & $\begin{array}{l}\text { Urine } \\
\text { Serum }\end{array}$ & 410 & 79 & $\begin{array}{l}38 \\
26\end{array}$ & 98 & 881 \\
\hline & & 20 & $\begin{array}{l}\text { Urine } \\
\text { Serum }\end{array}$ & 605 & 75 & $\begin{array}{l}52 \\
25\end{array}$ & 80 & 1,252 \\
\hline
\end{tabular}

are described, in two of which the patients were aged only 18 months.

Contrary to expectation, no alteration in blood phenylalanine was found to occur after administration of glutamic acid, though the total amount of phenylalanine and its breakdown products excreted in the urine was found to increase in all except one case.

No significant increase in intelligence was found after continued administration of glutamic acid in the two patients treated.

\section{Addendum}

Since this report was written it has been found that phenylpyruvic acid is partially broken down in vivo to phenylacetic acid and this is excreted conjugated with glutamine (Woolf, 1951). The excretion of conjugated phenylacetic acid by phenylketonuric patients is much higher than that of normal individuals, with the exception of a single case of phenylketonuria examined through the courtesy of Dr. B. H. Kirman. This patient (John R.) excretes a normal amount of conjugated phenylacetic acid and is also exceptional in having an intelligence quotient as high as 97 (Cowie, 1951). The phenylalanine content of his blood and urine are as high as is usual for these patients, and he excretes large amounts of phenylpyruvic acid. On the other hand, the most severely affected phenylketonuric idiot examined, with a social quotient of 3 , excretes more conjugated phenylacetic acid than any other patient examined. This suggests that the intellectual defect is due to an intoxication by phenylacetic acid. The condition might be curable if the in vivo conversion of phenylpyruvic acid to phenylacetic acid could be prevented.

We wish to thank Prof. A. A. Moncrieff and Dr. P. R. Evans for permission to publish the cases. One of us (L.I.W.) wishes to thank I.C.I. Ltd. for a research fellowship tenable at the Institute of Child Health, University of London.

\section{REFERENCES}

Albert K., Hoch, P., and Waelsch, H. (1946). J. nerv. ment. Dis., 104, 263.

Brugger, C. (1942). Schweiz. Arch. Neurol. Psychiat., $49,62$.

Christensen, H. N., Streicher, J. A., and Elbinger, R. L. (1948). J. biol. Chem., 172, 515. 
Consden, R., Gordon, A. H., and Martin, A. J. P. (1944). Biochem. J., 38, 224.

Coquet, M., Myle, G., Nyssen, R., and van Bogaert, L. (1944). Mschr. Psychiat. Neurol., 109, 133.

Cowie, V. A. (1950). Personal communication. , (1951). Lancet, 1, 272.

Delay, J., and Pichot, P. (1947). Ann. méd.-psychol., 105, II, 61.

,-- , Delbarre, F., and Taseel, J. (1948). Bull. Soc. méd. Hôp. Paris, 64, 669.

- - - and Bertagna, L. (1949). Ann. méd.psychol., 107, II, 320.

Fölling, A. (1934). Hoppe-Seyl. Z., 227, 169.

Jervis, G. A. (1937). Arch. Neurol. Psychiat., Chicago, 38, 944.
Jervis, G. A. (1939). J. ment. Sci., 85, 719. (1947). J. biol. Chem., 169, 651.

- - Block, R. J., Bolling, D., and Kanze, E. (1940). Ibid., 134, 105.

Munro, T. A. (1947). Ann. Eugen., Camb., 14, 60. (1950). Personal communication.

Penrose, L. S. (1935). Lancet, 2, 192.

- (1939). Ibid., 1, 572.

- (1946). Ibid., 1, 949.

- (1949). ' The Biology of Mental Defect.' London. and Quastel, J. H. (1937). Biochem. J., 31, 266.

Woolf, L. I. (1949). Unpublished. (1951). Biochem. J., 49, ix.

Zimmermann, F. T., Burgemeister, B. B., and Putnam, T. J. (1947). Psychosom. Med., 9, 175. 